\title{
Teaching and Learning English as a Foreign Language
}

\author{
Thara Mahmoud Ali Al-oglah ${ }^{1, *}$ \\ ${ }^{1}$ Department of Requirements, College of Islamic and Arabic Studies, Dubai, United Arab Emirates \\ *Correspondence: Department of Requirements, College of Islamic and Arabic Studies, Dubai, United Arab \\ Emirates. E-mail: ekremah@gmalc.ae
}

Received: April 18, 2018

Accepted: May 9, 2018 Online Published: July 20, 2018

doi:10.5430/ijelt.v5n2p57

URL: https://doi.org/10.5430/ijelt.v5n2p57

\begin{abstract}
The teaching and learning of a specific language whether it's considered foreign or second, has changed throughout the years. It began to transfer from a setting where the teacher was the basic and the role model into a setting where the learner would become the center or the focus. If we take in consideration all of these findings, methods, and approaches, in addition to the experiences which were created and further emphasized in an environment where learning will take place. Then this language would be used anywhere to create a sense of engagement. Particularly, in certain tasks which are of communicative nature while focusing on the interactive aspect. There had been a change in the way foreign languages came to be taught. That is, from the way the foreign language would be specified to a certain approach where we would calculate the competence and the performance of a learner. This has led to a shift from the tutor being the figure of authority, the specialized person, and the role model into the facilitator where he would guide students in the learning process to bring about change. The enhancements of today's time tend to focus on social media in addition to the current research being carried out. Moreover, public pedagogy is also very important and always creates a path towards constructing, bettering and increasing the level of competence of the learner when acquiring a specific language.
\end{abstract}

Keywords: foreign language, teaching, learning english, learner

\section{Introduction}

The teaching and learning of a language, regardless of whether it's foreign or second is defined as a process when a person learns a language that is considered non-native to him. That is, one which does not exist in the community where the person's language is typically spoken. There is often a major difference between what is considered as foreign and what is considered as second. A second language would typically refer to a language where the learner lives in the community where this language is typically used. Looking at it from a scientific point of view, in research, second language acquisition is defined as a language which is learned, with that language being typically foreign, in addition to exploring the human's mind and ability to learn other languages after they have acquired their native one. Many researchers and scholars have looked into this foreign language acquisition and what it means for a non- native speaker. Some of these fields included the following: education and anthropology, in addition to linguistics and sociology. Furthermore, psychology, and neurobiology has had extensive research regarding this. There have been many inquiries and research which led to the creation of certain ideas and innovations in order to provide certain insights on what would be considered successful strategies and methods to increase the proficiency and competence of a learner.

When a language is taught in a controlled setting such as a classroom and not spoken by the community, then this language would be considered a foreign language. Knowledge of another language would create a person who is able to maintain an interaction in a very creative and effective way. This also will lead to the learner participating in certain situations, which are authentic by using the typical language which is used in such an interaction. Furthermore, it would provide passages and open new doors, views and perspectives that are not limited to one person but to many more. It will also fasten and maintain the connections created across countries and continents in order to create Mutual Intercultural understanding. Since language is a vehicle which is responsible for one to one communication, this would lead to further mutual understanding of someone's culture, customs and language. When 
someone initiates the process of learning a language, this would provide him vast opportunities to acquire knowledge of social and linguistic nature in order to know the right time, place and manner for proper speech and creation of a constructive conversation (NSFLEP, 2014, P. 15). There is a further aspect between the two words acquisition and learning. With learning referring to a formal study of language being second or foreign in a controlled setting typically being the classroom, while acquisition is identified as a learning process which occurs naturally with no need of formal instructions. Here, there would be a typical difference between children acquiring language in an effortless procedure, and the difficulty adults encounter when learning a language in a formal setting. Foreign language is defined as the learning of another language which is not the mother tongue, nor the one spoken officially in the region by the majority of the population.

\subsection{Research Problem and Questions}

In general, teaching English as a foreign language is not a simple task and different factors contribute to difficulties and problems faced while teaching effective foreign language education. Therefore, this was the research investigation topic for many scholars around the globe. Hindi (2012) has said that teaching English language as a second language or a foreign is considered as a challenge for all teachers whether experienced or beginner. The role of suitable methodology in teaching of EFL was investigated and also it was found that the methods of teaching are the causes of the teachers' failure in helping their students to utilize English as a self-expression tool as in addition to achieve their communicative targets (Mukattash, 1983, P. 69). Researches that created by Suleiman (1983), Zughoul (1983) as well as Mukattash (1983) have confirmed this results with regard to Arab learners of EFL asserting that this category of learners face some problems because of implementation of the ineffective teaching methods. The similar findings have been shared through Aktas (2005) asserting that utilize of the instructional method in EFL learning contributes to difficulties and problems among the Arab learners. This can be because of the Grammar Translation method overuse by the EFL school teachers. Also, Alkhawaldeh (2010) has found that teachers of Jordanian English language school lack training in using modern methods professionally inside the classrooms that has negative effect on the learning and teaching process. So, this paper is conducted in order to answer the following questions:

- What are Language teaching approaches and how to be applied?

- What are Teaching and Learning methods of handwriting?

- What are Methods used to teach Vocabulary?

- What are Communicative Language Teaching Approach (CLT)?

- What are certain directions in the future regarding Languages which are foreign?

\section{Literature Review}

\subsection{Reinforcement in Teaching in addition to Research in Second Language}

Various researches has concluded that known information regarding the structure of language which is Illustrated in certain tests and quizzes, does not guarantee these learners' communicative abilities, since measuring this type of knowledge would be very arbitrary. Moreover, there were certain studies which have demonstrated that there is little match between the principles and them enhancing their knowledge in second language. Furthermore, many researchers have Illustrated and concluded that there are specifics of learning a second language which cannot be changed by using instructions. This non-native language which is also known as the procedures of the entire language shows how the SLA characteristics have progressed. Selinker (1974: 63) described inter-language as a system which exists on a continuum going across the mother tongue to reach the target language. Furthermore, another researcher named Corder (1978: 45) concluded that the learner in such a process of learning is constantly changing and leading to a change in the language system of innateness in order to bring the target language closer by a process called restructuring the continuum. This led the researcher to conclude that the majority of learners have shown proof that there is a transition from the mother tongue language to the target one. However, he stated that there was a certain uniformity regarding the way these learners progress. There is a certain uniformity regarding the procedures those learners perform while following the same sequence of steps in order to develop their potential, but the mother tongue did not play any crucial part. This is what is known as the developmental continuum.

However, new findings contain evidence that the acquisition paths of the two linguistic systems of the learners are influenced by a rich interplay of mostly universal (as opposed to language-specific) factors and show similarities unrelated to the first or second language (2010: 12). Newest studies and researchers in the field of inter language 
such as Vidaković's research, where he applied the findings on Serbian learners who took on English as foreign language to further emphasize what Corder found in his research. This means that the learners' inter language consists of a developmental procedure in addition to it being systematic when developing takes place. By contrast, new researches provided proof that the acquisition process of two linguistic systems are affected by universal factors of rich interplay to demonstrate that there are no differences related between the native and the foreign language (2010: 16).

When talking about the SLA field there is a controlling factor which is very important. That is the innate ability which early humans hold. Pica (1983: 96) stated that learners in all languages go through the same procedure with a fixed set of steps. This is known as the sequence of development, which is used to learn certain subsystems. These include the order of words, the clauses and their types in addition to negation. A simple example on negation in the English language was evident upon looking thoroughly at communicative samples. This demonstrated that learners of a foreign and second language went through the same exact steps to be defined in what is called as negation and its placement. The researcher scanned many studies in Japanese, Norwegian in addition to the Spanish and German languages which covered children, teens, and grown up learners.

He discovered that all learners who attempt to learn English go through these steps as follows: The phase of the word no in an example such as "no water" to later include it in a phrase such as "I no can cook". This would be considered as step two. In step three, the negation would be accompanied by models in an example such as "I can't play this one". In step four, the system of auxiliary is created and the learner is taught the appropriate use of not. A clear example of this is the following, "He doesn't know anything". This provides evidence that Learners tend to create particular mistakes at certain stages when acquiring and learning a structure. Each procedure would emphasize a certain type of structuring inside the learners' mind.

Structure would improve as time passes. One should pose a question of the ability to learn without principles. When principles are non-existent and it takes knowledge from a driven process which is created by the mind, then it is certainly possible but it does not assure that there would be a systemic principle that is taught. More research should provide data regarding all angles of a language being second or foreign, as to whether learning is equal by implicit methods or the fact that these aspects are more complicated to require a process which is more driven conceptually to achieve full association (Ellis, 2002, P. 24).

\subsection{Language Teaching Approaches}

Methods which are used in teaching a language such as English has changed over the years, the context became important and the competence was the goal. Teachers of a language have decided to follow and implement different approaches. These approaches are illustrated as follows:

\section{Grammar translation approach.}

This approach was implemented by the tutor in order to teach children grammar. This is where this tutor would begin to explain every single word using the mother tongue in order to make them understand English. However, one disadvantage of such a method would be the fact that the teacher would end up concentrating on the native language rather than the target one. It has also led to the classroom setting seeming as though it is for a native language session and not the target one. In this method, tutees would only benefit from using this method in a limited way. We should note that it is still used until today by many schools especially in rural locations in various places, such as India. Furthermore, it is also thought and supported by other approaches in order to teach the native language in our schools.

2. The bilingual approach.

Here, this method is considered as the most successful and favorite in our schools, since they most use such a method in order to teach students from various schools in India. Here, the teacher would begin by explaining and illustrating all the English sentences. He would then continue and require from students that they apply specific activities in the English language. It should be known that there was a certain misconception which stated that the teacher would only be available to assist students and the tutees were not allowed to use it. Regardless, this method is usually applied on paper and not in a setting such as a classroom where a tutor would begin to create certain English segments which are abundant. This is in order to assist by using the native language in sentences which are provided to them. It was found that this method would not assist and develop the fluency of the natural language. It did however conclude that such an approach would be put to good use in helping students learn the target language but only to a very specific extent. 


\section{The Direct method.}

This was used by tutors back in the day to implement this method in order to teach students of Indian origin. It was used vastly in private schools where the tuition was usually higher. Here, these tutors will only implement a certain practice by using English segments without putting any dependence on the native language. The teacher here is not allowed to use the native language, not even a single segment of it. This method led students to encounter various difficulties since they came from various environments and had no previous knowledge of English. This difficulty was mostly regarding specific words and what their meaning carried. With that being said, this approach was considered the most useful and successful out of all, since it creates an environment where students can engage in conversation in the classroom setting. All of these methods carry specific strong points and other weak ones. One, would be the fact that when students would end up learning the English, this knowledge would consider English language as a subject instead of language on its own way. Moreover, they did not have the ability to always implement what they have learned to put into practice due to not having authentic environment where they can practice. Furthermore, with all these above challenges, the tutor would have only specific hours which would not be enough in order to provide perfect explanation and emphasis on what language is all about; since these hours would only be constricted to a minimum of two and a maximum of six sessions per week. So, these became examination oriented and that was it. Another problem which was noticed in Indian tutors was the fact that some of them were not aware of the recent developments which have occurred in the field of ELT pedagogy. All in all, these challenges are very visible and huge since these tutors are expected to cater to all these tutees' needs in order to make them have fluency and confidence that is enough to allow them to communicate with one another. These problems are also visible and various and there is a need to train them and inform them of all the strategies which they can apply in order to teach and allow students to learn perfectly.

\subsection{Implementing Strategies and Combining Them with Teaching Approaches}

Research came to conclude that students are learning the language at various paces, since their level of competency is very different from one another. We cannot hold the tutor responsible for this, since he aims to provide and give everything and does his best to teach students. With that said, we should know note that can put a little bit more effort in order to motivate them and ensure that they become interested in learning. Since learning is considered an active process where knowledge, in addition to skills and insight is transformed into what we call behavior. Cawley and partners of his, have found that there are three fields. The first would be affective, and the second being psychomotor, while the third would be learning cognitive. We should note that, one can choose any of these depending on their preferences in order to learn while taking in consideration the environment they exist in. Therefore, these came to be known as styles of learning. We should note that learning would occur faster and be sustained longer if it is provided to the learners in a way which they would prefer in order to meet their needs. All this is used to increase competency and improve their abilities. These two researchers, Claxton and Murrell concluded that the style must match between the teacher and the student in order to create a productive environment where learning is emphasized. We should note that the tutor must have knowledge of the styles which the students prefer in order to change his method and adapt it to what would suit the learners' needs. Boylan States that learning would have better results if the teachers were very aware all of the strategies they should apply when teaching in a classroom. Moreover, there was a specific research regarding this area where the researcher Davis came out to conclude that students can learn the procedures the tutor will implement in the classroom in order to develop learning and make it more efficient, regardless of what the teacher chooses to use as the style.

Student can apply various attitudes and they can become very conscious to the strategies which can be implemented. Many researchers have identified what language strategies actually means, (Wenden and Rubin,1987, P. 23) defined it as various operations, plans, drills which facilitate learners into acquiring, receiving, storing, and applying the information. Many researchers (Richards, Platt and Platt, 1992, P. 63) have discussed that learners tend to intentionally use certain strategies and implement different techniques in order to help them learn something new, regardless of whether it is information, data or simply any knowledge needed to be remembered.

Other researches provided simple and detailed illustrations (O'Malley and Chamot, 1990, P. 85) regarding individual's behaviors and their mental thinking which would help them better the way they understand, learn or maintain the new information. Therefore, learning techniques have always been considered as a special method which is used to process information in order to better comprehension, what is being learned and making sure that it remains stored in the memory. (Oxford, 1990, P.19) goes on to identify language learning as a special strategy which is undertaken by the student in order to make learning fun, more productive, and help him/her acquire that knowledge in the shortest time possible in addition to helping the specific type of knowledge be transformed to 
various incidents and situations. It is considered a reflection of what a learner is able to do, and what he intends to do and illustrate the specific actions that need to be taken. Since second language acquisition started being studied rigorously in the 1970s, it led tutors and researches to emphasize and come to a conclusion that there is no method that would fit all, but there are various ones which are used in language teaching and implemented, in order to reach findings to mark the beginning of a success, which is universal in tutoring a second language (Brown, 2007, P. 16). We should note that there are certain cases where students seemed to succeed in any method they tended to implement, overtake, in order to confirm that there are certain learners who are gifted with extraordinary abilities that would help them succeed and develop further while others were not so fortunate in that regard.

Many researches were conducted and observations were recorded, and this allowed the researchers (Rubin, 1975, P. 77; Stern 1975, P. 56; Rubin and Thompson, 1994, P. 49) to elaborate and list what great learners are like from taking in consideration not only their personal characteristics, but also the style and strategy. Here is what great language learners do:

- They rely on themselves and take responsibility for what they have to learn.

- Arrange and sort out all the information that is related to language.

- They are innovative, and always sense language by practicing its words and the grammar of that language.

- They find opportunities to practice and take a chance out of every encounter they come across, in and out of the classroom.

- Keep on practicing and learning even though they do not comprehend every word, so they can better themselves.

- Revise and use techniques in order to retrieve what they have memorized.

- Learn from the mistakes they commit, and not letting those mistakes hold them down.

- Use all the knowledge they have, whether linguistic or not; especially their first language in order to help them learn the second one.

- Take advantage of cues which would help them comprehend better.

- Practice creating intelligent answers and guessing whenever they come across a barrier.

- Learn language regardless of whether it is chunks, words or segments. All this would help them formalize routines in order to perform and demonstrate their abilities.

- Learn to practice and employ certain gimmicks in order to help them keep the conversation flowing naturally.

- Learn specific techniques to aid them when they come across certain gaps and barriers in their competence.

- Acquire various styles and methods of speech as these can be deployed across many settings where the levels of formality may be important.

\subsection{Teaching and Learning of Certain Methods and Techniques of Handwriting}

In certain settings, where there is a main focus on the skills taught, since it is considered a special skill on its own, handwriting tends to be tutored by using specific auditory and visual demonstrations on how letters are drawn and written. In other words, tutees tend to focus on hearing and visualizing the order and how it is described in addition to the directions of certain letters. After that, they begin what we call the practicing phase where they begin to apply what they have learned through certain steps such as follow:

- A process known as tracing where students begin to track how letters are written beginning from one point and ending in another, they also take in consideration the direction in addition to the certain counts of strokes since they are being tutored using very small steps and techniques like using numbers, or more easily the use of arrows.

- A process known as copying where in this phase students/learners tend to copy a certain paradigm or sample letter, which has been drawn several times, over and over again. This method which is considered very effective when used to tutor learners, which their native language is Arabic, in order for it to succeed; students should transfer from the specific skill to meaning by going through certain procedures, which are described as follows: 
1. The first step would be the way a letter is presented. Here, the tutor begins to demonstrate how letters are written one at a time in order to take advantage of the visual, tacit aspect, in addition to the specific auditory and kinesthetic modals for the intended students.

2. Using a specific context where words and segments would be read and written in order to help in the way certain letters are written or read. Here, the tutee begins to copy in addition to reading the certain letters which were illustrated to them, all is done at once not only for those but for many others as well. We use arranging and reordering of a group of words and then replicate them from a substitution diagram which is usually a table in order to create very accurate sentences that carry meaning.

3. Using a specific context where words and other segments would help in writing and reading, to specific letters in big paragraphs. Here, students begin to practice how letters are created by reading through mixed sentences and attempting to write them again in order to create a meaningful text. In addition, a student can also try filling words in a certain text which contains missing words and then begin to write an introductory statement for a following segment in that same text.

\section{Methods Used to Teach Vocabulary}

In classrooms where there is focus on certain skills, vocabulary and words tend to get tutored not in groups, and not in a contextualized manner. The methods used are continuant, taking in consideration the definition in order to aid the way these words are analyzed from a structural and morphological point of view. Certain exercises are used with these procedures. Those which have been adapted from various sources are written down as follows:

1. Create segments of meaning in order to analyze such segments by using suffixes, prefixes, certain base words and certain word inflections.

2. Categorize words which are compounds into two categories, one being free and the other being bound. In other words, Focusing on those words which can be stranded and those which cannot.

3. Using basic words and add many additions to create unlimited amount of words by using affixes.

4. Creating words by adding suffixes and prefixes which are compatible with the definitions provided.

5. Take advantage of analogies in order to link unknown words to the known ones.

6. Using adjectives and creating adverbs out of them.

7. Identify the acronyms with the appropriate expressions.

8. Identify contractions in order to match them with the suitable meaning.

9. Practicing in the creation of various verbs, which differ in tense using root verbs.

10. Creating words which are different in numbering such as singular and plural.

This method states that if one were to tutor words without the context, this would lead to creating a formula, which is suitable as a representation in the mind leading to it being stored for a longer period of time in the memory. Ormrod (1986: 96) states that, in the case where words are used without a context; students would put more focus on them, leading to a direct learning based solely on the specific words provided. Two researchers Gough and Juel (1991: 106) also stated that "what the child needs is a way to recognize novel words on the basis of their form rather than their context".

\subsection{Teaching and Learning of Certain Methods and Techniques of Spelling}

In classrooms where there is focus on teaching skills, tutors end up teaching rules of spelling by using certain techniques such as drills. Since this approach focuses only on students' attention regarding spelling, it has certain disadvantages. One disadvantage would be that it focuses only on spelling and ignores other aspects such as communication. Another disadvantage is that spelling has too many principles and various exceptions to those rules leading to difficulty in learning (Parry and Hornsby, 1988, P. 33; Smith, 1982, P. 49).

Therefore, it is obvious that we are in need of a specific method which would transfer instructions and rules from being direct into actual applications of those rules. Here are specific steps for this certain approach.

- The first step would be to demonstrate the principles of spelling by providing students with instructions, one instruction at a time. 
- The second step would be to teach students how to spell by reading certain texts where students observe and notice how these principles are illustrated to them, one by one. Then, they get reinforced through the reading passages. This would lead to the enhancement in visual Imaging of these words in that certain text.

- The third step would be to create and practice spelling rules by writing. Here students would focus on the principles which were illustrated to them earlier in stage two. Then, they are asked to begin composing a certain text regarding a specific topic which is chosen by the teacher while putting focus on using words which they are not aware of their spelling.

\subsection{Teaching and Learning of Certain Methods and Techniques of Grammar}

In classrooms where there is focus on teaching skills, tutors end up teaching rules of grammar by explaining them explicitly and require students to practice them though exercises of mechanical nature.

These exercises are composed of specific sentences, which are not related to one another in any form. They are illustrated as follows:

1. Practices of substitution where students receive sentences, which are very specific and they are required to pick out certain word segments which are available. This is done one by one.

2. Exercises of transformation where students receive the opportunity to create certain sentences in various ways from sentences and words which were already provided to them.

Acquiring grammar is a very important and hard task which demands a lot of energy in order to perfect your own writing. What is even more difficult is the fact that the procedure of acquiring grammar would actually lead to problems with writing as the student ends up focusing on not making mistakes when writing words, phrases, and sentences, to forget all about the ideas and the creative aspect of writing. However, this is very important and crucial in order to achieve writing that is perfect. The majority of people would not benefit from this, since writing not only focuses on not making mistakes when writing, but it also requires very professional and accurate writing that carries creativeness.

Omaggio (1986: 96) provides and concludes that there should be Focus on grammatical proficiency in addition to appropriate and creative communicative opportunities. We should note that these communications are not perfected without having certain grammatical proficiency.

This View was actually concerned and discussed by Pachler and Bond (1999: 56), since they came to the conclusion that teachers provide materials and teaching methods while students tend to focus on the grammar that they learn and acquire, in addition to developing the knowledge they have by providing a creative and Interactive environment in the classroom. In this method, grammar should be practiced not only for communicative purposes but it should create a specific transfer from teaching these grammatical principles in order to turn them into rules which would be used to convey meaning in communicative situations. Here are the steps for such a procedure:

- Presenting these principles: Here, the teachers Illustrate these rules one by one, as this step is considered the basic step which prepares for the upcoming two steps.

- The second step would be to understand the grammar which exists in the full texts. Here, the teacher would present paragraphs that are written alongside a recording where the grammatical principles are explained step by step. When reading such a text, the learner would emphasize the meaning which is provided by the tutor. They also try to locate certain principles by themselves.

- The third step would be to use grammar in order to create full paragraphs where the learners can put to use the principles which they learned and the ones which they located. This is essential in order to create full texts using the skills and information they have learned in the previous two steps.

\subsection{Teaching and Learning of Certain Methods and Techniques of Pronunciation}

In relation to what we have presented before, we should note that the writer offers an explanation and he mentions that language exists as a whole in addition to phonics. These are regarded as very significant. None of them would be as important without the other. Moreover, this method focuses on the transfer which occurs from illustrating principles into realizing and ultimately producing and creating full proficiency in spelling to ultimately write proper paragraphs and texts. Here is the procedure explained in the following steps:

- The first step would be to present these pronunciation principals where the teacher would illustrate them one by one. We should note that these principles are of great value to the learner. 
- The Second Step would be to realize the pronunciation using full paragraphs. Here, the teacher would give learners certain and specific phonological principles that were illustrated to them in the previous step. Students begin to hear and would emphasize on what is being heard in a specific context in order to learn the appropriate pronunciation of such segments.

- The third step would be to create full texts where the learners would use the principles that were provided to them and the ones, which they located by themselves in order to create role playing, to mimic situations in real life where communication would be needed.

\subsection{Certain Directions in the Future Regarding Languages Which Are Foreign}

There is a certain aspect which brings controversy even to this day. This exists in the world of language teaching regardless of whether a language is second or may be foreign. This is illustrated by posing a question as to whether native proficiency and perfection is necessary and needed in today's multi global world we exist in. In other words, taking in consideration the field of EFL, should we obey and follow the norms and rules which were posed on by native speakers of the English language? This has been considered and studied by many over the years while considering the extraordinary use in such international context (Timmis, 2002, P. 51). Regarding this problem, many researchers and people of interest in this area have posed a question as to why do we consider native speakers as the model, and why are the communities which they are involved in consider the suitable aspect for learners of the English language when considering it as an international one. As a response to these questions which were posed, there have been many terminologies which got introduced. Example of such would be Global English, World English, in addition to international and international English which is standard and finally world Englishness where some of these face and bring about an idea to make us think as to why the only communities which are appreciated and considered are the ones of native speakers (McArthur, 2001, P. 12). For example the term Global English would expand this idea that this language is only for the people who use it, regardless of the way they use it.

\section{Communicative Language Teaching Approach (CLT)}

Daisy (2012) mentioned that CLT is regarded as a method used to teaching languages that are second or foreign; to put an emphasis on the interactions as those would help in learning languages. Richards and Rodgers (2001) stated that CLT has a purpose of that it "aims to (a) make communicative competence the goal of language teaching and (b) develop procedures for the teaching of the four language skills that acknowledge the interdependence of language and communication" (p. 155). Such an approach would be considered efficient in the theoretical model of English language teaching since the 1970s. These two researches had also stated that in such an approach, language would carry social meaning in addition to the functional meaning. This means that knowing the social meaning and communicative functions in addition to the linguistic forms would be considered very crucial. This also means that language learners must be competent in order to link the linguistic forms alongside the nonlinguistic information in order to consider the meaning, which the speaker means when speaking (Littlewood, 1981). Littlewood (1981) suggested a very important and typical aspect of the CLT would be to put emphasis on the structural and functional aspects of a particular language. CLT depending on the concept of communicative competence of Hymes's (1966) as considered an extension from Chomsky's (1965) concept regarding the linguistic performance and competence. Hymes (1966) stated that it is not sufficient for the tutor to have competency in the grammar or linguistics of a language by itself when it comes to putting it to use in a social and cultural context. This means that the context where the language is put to use is very important when learning language. Howatt (1984) mentioned that "The Communicative Language Teaching stresses the importance of providing learners with opportunities to use English for communicative purposes and attempts to integrate such activities into a wider program of language teaching" (p. 27). This means that the learning goals in addition to the instructional goals would be the aim of communication, since there's an assumption that language is not isolated from its context. Therefore, language learning and teaching must be accomplished in the specific context, since focusing on learning and its communicative competence would be what is common nowadays globally.

\subsection{Emphasizing Fluency Rather than Accuracy}

The goal of the communicative language teachings is to provide competence in communication, by enhancing fluency. This is regarded as using language naturally upon conducting an interaction to keep communication going even though there is limitation in the speaker's communicative competence. This would have a consequence on the CLT, as it has been heavily criticized from tutors as there is prejudice that favor native speakers of the language, or perhaps those tutors who let go of the grammar translation method (Chang, 2011). Harmer (2003) stated that this 
approach erodes the specific grammar teaching leading to loss in accuracy and precision when enhancing the level of fluency. This methodology would put too much emphasis on the fluency rather than accuracy. A clear example of this is the attitude when students make mistakes, as before they would be seen as failures on both teachers and tutees. Here, such errors are considered progress rather than mistakes. Regarding this approach, such mistakes would give us an idea of how the learners develop and progress in their learning, since those could be due to the interference of the native language. This is by tutees lacking behind on their knowledge of their native language to help solve issues in the target language, even though they have no full proficiency of that language. Another reason could be due to the overgeneralization that they implement to what they learned in their target language. There is evidence that overgeneralization in addition to transfer are strategies used in the foreign and second language learning.

\subsection{Emphasizing Rather than Knowing}

Similar to Widdowson (1990, p. 159), the CLT approach "concentrates on getting learners to do things with language, to express concepts and to carry out communicative acts of various kinds." By assuming learners would know the rules when actually knowing the language, but that is wrong as Widdowson (1990), states that "the grammar, which they must obviously acquire somehow as a necessary resource for use, proves elusive. So quite often the situation arises where learners acquire a fairly patchy and imperfect repertoire of performance which is not supported by an underlying competence" (p. 161). To mean that learners not always infer the information regarding the language system out of the communicative activities they perform, as it leads to sacrificing knowing, or the "Grammatical knowledge did not always follow as a necessary corollary of communication." (Widdowson, 1990, p. 165).

\section{Discussion and Conclusion}

Handwriting is not only a mechanical, lower-level skill but also a meaningful process. Accordingly, the integration of the skills-based approach and the whole-language approach can boost handwriting performance above the levels that occur with either alone. In support of this view, Farris (1991) states: [Handwriting] instruction is more efficient while ... instruction is more in line with the philosophy of whole language. However, without being introduced to and given instruction in the basic handwriting skills such as letter formation, alignment, slant and size, children are left to discover such skills on their own. As such they develop inappropriate techniques and legibility suffers. (pp. 313-314)

Research indicates that both the skills-based approach and the whole-language approach increase vocabulary achievement. Some studies obtained positive results with the skills-based approach. These studies revealed that: (1) Morphological generalizations help students determine the meanings of unknown words (Wysocki and Jenkins, 1987); (2) Explicit instruction in context clues enhances students' ability to determine the meanings of unknown words from the context (Askov and Kamm, 1976; Huckin and Jin, 1987); (3) Phonics instruction positively affects word recognition. The results of the above studies can be interpreted in light of the abilities of students participated in these studies. In support of this interpretation, research has shown that better readers profited more from context than did less skilled readers. Jenkins, Stein and Wysocki (1984).

Also, the results of the previously-mentioned studies provide evidence in support of the author's view that direct instruction and contextual learning can add significantly to the vocabulary of students of all ability levels. In support of this view and from their survey of research dealing with the conditions of vocabulary learning, Beck and McKeown (1991) concluded, "No one method has been shown to be consistently superior.... [and] there is advantage from methods that use a variety of techniques" (p. 805).

As shown above, research in the area of spelling provides indirect evidence that instead of either-or planning of spelling instruction, the comprehensive approach can be more effective in increasing spelling achievement. Direct support for the comprehensive approach to teaching spelling comes from studies done by Castle et al. (1994), Rosencrans (1995) and Shefelbine (1995). Castle et al. (1994)

In addition, providing phonemic-awareness instruction within a whole language program had significant effects on spelling and reading performance. Rosencrans (1995) found that direct instruction within a whole language spelling program increased children's spelling achievement. Shefelbine (1995) found that combining temporary (invented) spelling with systematic, formal spelling instruction resulted in more rapid growth in both correct spelling and word recognition than did either approach alone.

Viewed collectively, research in the area of grammar shows that grammar can be regarded as both a skill and a process and that a combination of form and meaning can contribute to higher levels of accuracy and fluency. In support of the comprehensive approach to teaching grammar, some studies found that students who received explicit grammar instruction within communicatively organized classrooms showed greater accuracy in subsequent use of the 
grammar points taught to them than students who received form-oriented instruction alone or no form-oriented instruction at all (e.g., Bernardy, 1998; Lightbown and Spada, 1990; Montgomery and Eisenstein, 1985; Spada, 1987; White, 1991; White et al., 1991).

In the end, it can be concluded that a learner should always be careful and pay attention to the techniques, methods, and approaches provided by the teacher in order to facilitate learning. Moreover, this can aid them to better their efficiency and learning. Finally, combining these two would allow learners to further improve and develop by following these instructions to the letter. The teaching and learning of a specific language whether it's considered foreign or second, has changed throughout the years. It began to transfer from a setting where the teacher was the basic and the role model into a setting where the learner would become the center or the focus. If we take in consideration all of these findings, methods, and approaches, in addition to the experiences which were created and further emphasized in an environment where learning will take place. Then this language would be used anywhere to create a sense of engagement.

\section{References}

Chamot, A.U. (2004) Issues in language learning strategy Research and Teaching. Electronic Journal of Foreign language Teaching, 1(1), 14-26.

Corder, S.P. (1978). Language-learning language. In: Richards, J.C. (Ed.), Understanding Second and Foreign Language Learning: Issues and Approaches. Newbury House, Rowley, MA, pp. 71-93.

Ellis, R. (1986). Understanding Second Language Acquisition. Oxford University Press, Oxford, UK.

NSFLEP. (2014). World Readiness Standards for Learning Languages (WRSLL). Alexandria.

Oxford, R.L. (2003). Language Learning styles and strategies: An overview. Learning Styles and Strategies/Oxford, GALA, 1-25

Pica, T. (1983). Adult acquisition of English as a second language under different conditions of exposure. Language Learning, 33, 465-497. https://doi.org/10.1111/j.1467-1770.1983.tb00945.x

Selinker, L. (1974). Interlanguage. In: Schumann, J.H., Stenson, N. (Eds.), New Frontiers in Second Language Learning. Newbury House, Rowley, MA. 